\title{
Interleukin 7 receptor gene polymorphisms and haplotypes are associated with susceptibility to IgA nephropathy in Korean children
}

\author{
WON-HO HAHN ${ }^{1}$, JIN-SOON SUH ${ }^{1}$, HAE-JUNG PARK ${ }^{2}$ and BYOUNG-SOO CHO ${ }^{1}$ \\ ${ }^{1}$ Department of Pediatrics, and ${ }^{2}$ Kohwang Medical Research Institute, School of Medicine, \\ Kyung Hee University, Seoul, Republic of Korea
}

Received June 3, 2011; Accepted July 18, 2011

DOI: 10.3892/etm.2011.322

\begin{abstract}
An abnormal T-cell response is involved in the pathogenesis of various renal diseases. Survival of naïve $\mathrm{T}$ cells is dependent on interleukin 7 (IL7) and its receptor (IL7R). Thus, we investigated the association between IL7R single nucleotide polymorphisms (SNPs) and childhood IgA nephropathy $(\operatorname{IgAN})$. We analyzed the genotypic distributions of two missense SNPs of IL7R, rs1494558 (Ile66Thr) and rs1494555 (Val138Ile), among 198 pediatric IgAN patients and 288 healthy controls. Haplotype analysis and measurement of pair-wise linkage disequilibrium were performed. In addition, the genotypes of patient subgroups, determined by the presence of nephrotic range proteinuria $\left(>40 \mathrm{mg} / \mathrm{m}^{2} / \mathrm{h}\right)$ and pathological advancement, were analyzed. The genotyping data of IgAN patients and controls showed significant differences in rs1494558 (codominant, $\mathrm{P}=0.0003$; dominant, $\mathrm{P}=0.0003$ ) and rs1494555 (codominant, $\mathrm{P}=0.0038$; dominant, $\mathrm{P}=0.0099)$. In the haplotype analysis, $\mathrm{AC}$ (codominant, $\mathrm{P}=0.0066$ ) and GT (codominant, $\mathrm{P}=0.0005$; dominant, $\mathrm{P}=0.0006$ ) were significantly associated with susceptibility to $\operatorname{Ig} \mathrm{AN}$. Furthermore, in the analysis of clinical subgroups of IgAN patients, rs1494558 was associated with nephrotic range proteinuria (codominant, $\mathrm{P}=0.027$; recessive, $\mathrm{P}=0.023$ ). Our results suggest that $I L 7 R$ may be associated with disease susceptibility and proteinuria in childhood $\operatorname{Ig} \mathrm{AN}$.
\end{abstract}

Correspondence to: Dr Byoung-Soo Cho, Department of Pediatrics, East West Kidney Diseases Research Institute, School of Medicine, Kyung Hee University, Hoegi-dong \#1, Dongdaemun-gu, Seoul 130-702, Republic of Korea

E-mail: bscho@dreamwiz.com

Abbreviations: GN, glomerulonephritis; IgAN, IgA nephropathy; $I L 7 R$, interleukin 7 receptor gene; $\mathrm{LD}$, linkage disequilibrium; SNP, single nucleotide polymorphism

Key words: childhood, IgA nephropathy, interleukin 7 receptor, polymorphism, proteinuria

\section{Introduction}

Primary $\operatorname{Ig}$ A nephropathy ( $\operatorname{Ig} \mathrm{AN})$ is the most common glomerular disease in children and adolescents who undergo renal biopsy because of isolated microscopic hematuria or hematuria associated with non-nephrotic proteinuria (1). Even though the exact pathogenesis is not yet known, $\operatorname{IgAN}$ is characterized by glomerular mesangial proliferation in response to the deposition of IgA. While the disease is characterized by a single histopathological finding, patients with IgAN show variable clinical and histopathological features. Polymorphisms of candidate genes influence this individual variability. To date, there has been evidence suggesting that abnormal immune responses play an important role in the pathogenesis of $\operatorname{IgAN}(2,3)$.

Interleukin 7 (IL7) is a well-known essential factor for the development and maintenance of the immune system. IL7 works through its receptor, IL7R (also known as CD127). IL7R, a member of the hematopoietin receptor family, is a type 1 membrane glycoprotein capable of binding $\alpha$-helical cytokines (4). Signaling via IL7R induces somatic recombination of the T-cell receptor and immunoglobulin genes, promoting both the proliferation and differentiation of developing $B$ and T lymphocytes. The IL7R is heterodimeric and consists of the IL7R $\alpha$ chain (IL7R $\alpha$, encoded by IL7R) and the common cytokine-receptor $\gamma$ chain $(\gamma c$, encoded by $I L 2 R G$; also known as CD132). IL7R $\alpha$ transduces transmembrane signals through the recruitment of intracellular messengers to its cytoplasmic tale. IL7R $\alpha$ is expressed on immature B and T cells, and genetic ablation or the presence of neutralizing antibodies has been found to block lymphocyte development (5). In addition, mutation of IL7R $\alpha$ has been implicated in the development of a subtype of severe combined immunodeficiency. Functionally, IL7R $\alpha$ is important in the body's innate and adaptive inflammatory and immunological response. This signaling is critical for T-cell differentiation of $\mathrm{CD}^{-}{ }^{-\mathrm{CD}} 8^{-}$thymocytes and has a role in the survival of $\mathrm{CD} 4^{+} \mathrm{CD} 8^{+}$cells after positive selection. Moreover, IL7 signaling modulates peripheral memory or naïve T-cell homeostasis (6) and production of several proinflammatory (IFNr, IL2) and anti-inflammatory cytokines (IL4) (7). Even though the downstream signaling pathway of IL7R remains poorly understood, previous studies have shown that it leads to activation of the phosphatidylinositol- 
3-kinase pathway, the Ras/Raf signaling cascade and Janus kinase/STAT pathways, which have all been suggested to be important for the pathogenesis of various diseases, including IgAN $(8,9)$. In addition, the IL7/IL7R pathway has been studied as part of the pathogenesis of various autoimmune diseases, such as multiple sclerosis (MS), rheumatoid arthritis (RA), systemic lupus erythematosus (SLE), sarcoidosis and psoriasis $(10,11)$.

Accordingly, the IL7/IL7R pathway is a very attractive target for inflammatory disorders, and its genetic variations have been proposed to be involved in the pathogenesis of various autoimmune diseases $(10,12)$. However, no prior study has investigated the association between SNPs of IL7R and renal diseases, especially in children. Thus, the present study was conducted to investigate the association between polymorphisms of the $I L 7 R$ gene and childhood IgAN.

\section{Materials and methods}

Patients and controls. We evaluated 198 Korean pediatric patients with biopsy confirmed IgAN [12.64 \pm 5.17 years (mean age \pm SD); 118 boys, $13.36 \pm 4.97$ years; 80 girls, $11.58 \pm 5.31$ years] and 288 healthy controls ( $37.53 \pm 13.26$ years; 156 males, $39.46 \pm 14.60$ years; 132 females, $35.25 \pm 11.11$ years). Patients were identified through a school screening urinalysis; most had no symptoms of glomerulonephritis (GN) other than abnormalities on the urinalysis. Therefore, they were identified at a relatively early stage of the disease.

Healthy controls were recruited based on the results of routine screening. This screening included the completion of a questionnaire that addressed symptoms and medical history, and several laboratory test findings, including the results of a urinalysis (protein, glucose and occult blood). Control candidates with an abnormal result on any item were excluded.

There was a difference in mean age between our cases and controls (12.64 \pm 5.17 vs. $37.53 \pm 13.26$ years, respectively). However, we were unable to enroll age-matched controls. IgAN is known to develop in the third decade; therefore, healthy controls $>20$ years of age were required to avoid the recruitment of individuals with undetected or sub-clinical IgAN. Accordingly, the presence of a substantial age gap between cases and controls appears unavoidable in studies on pediatric IgAN. Other researchers have also utilized adult controls in studies on SNPs in childhood $\operatorname{IgAN}(13,14)$.

Patient subgroups. To determine the nature of the association between SNPs of IL7R and the development of severe proteinuria, the patients were divided into subgroups according to the presence of nephrotic range proteinuria during the course of $\operatorname{IgAN}\left(>40\right.$ and $\leq 40 \mathrm{mg} / \mathrm{m}^{2} / \mathrm{h}$ ).

Furthermore, we created subgroups of the IgAN patients according to the presence of podocyte foot process effacement on renal biopsy. In addition, IgAN patients were divided into pathologically mild (Grade I-II) and advanced (Grade III-IV) disease groups to evaluate the association of IL7R SNPs with disease progression as determined by the modified H.S. Lee histological grading system (15). Demographic characteristics of the IgAN patients are shown in Table I. This study was approved by the Ethics Review Committee of the Medical Research Institute, Kyung Hee University Medical Center,
Seoul, Korea. Written informed consent was obtained from all subjects and parents or legal guardians.

SNP selection and genotyping. The missense SNPs of the $I L 7 R$ gene were selected based on the findings of extensive database searches (http://www.ebi.ac.uk/ensemble/, http://ncbi. nlm.nih.gov/SNP, BUILD131), based on a heterozygosity $>0.1$ and a minor allele frequency of $>0.05$ in the Asian population. The SNPs were also validated by HapMap database.

Genomic DNA was extracted from the whole blood of each subject using the DNA Isolation kit for blood (Roche, Indianapolis, IN, USA). Genomic DNA was amplified using specific primers: rs1494558 (sense, 5'-TGTCTGCCACAGAGTCTGCTAT-3'; antisense, 5'-GTGAAGGACAAGGAGTTTCAGG-3'; 395 bp) and rs1494555 (sense, 5'-TCAAAGTGACTTGCAGAGGAGA-3'; antisense, 5'-GGAAATGCACTACTAGGCCAAC-3'; $326 \mathrm{bp}$ ). Polymerase chain reaction (PCR) products were sequenced using the ABI PRISM 3730XL analyzer (PE Applied Biosystems, Foster City, CA, USA). Sequence data were analyzed using the SeqManII software (DNAStar Inc., Madison, WI, USA).

Statistical analysis. For the statistical analysis of pathological grading in patient subgroups, the SPSS Statistics 17.0 software package (SPSS Inc., Chicago, IL, USA) was used, and a P-value of $<0.05$ was considered statistically significant.

For the case-control association study, Hardy-Weinberg equilibrium (HWE) for all SNPs was assessed using SNPstats (Biostatistics and Bioinformatics Unit, Barcelona, Spain) in both cases and controls (16); the SNPs not in HWE $(\mathrm{P}<0.05)$ were excluded from the analysis. For the logistic regression analysis and trend test, SNPstats and SNPAnalyzer (Istech Inc., Goyang, Korea) were used. To show alternative effects of the variants, logistic regression analysis was performed in the three analysis models (codominant, dominant and recessive). Allele frequencies of each SNP were compared by Pearson's Chi-square test. To reduce experimental error, we calculated sample power for the SNPs and the number of cases was adjusted to achieve $80 \%$ power $(\alpha=0.05$, genotype relative risk = 2-fold) using a genetic power calculator (http://pngu.mgh. harvard.edu/ purcell/gpc).

A linkage disequilibrium (LD) block of polymorphisms and haplotype analysis were tested using Haploview version 4.2 (Broad Institute, Cambridge, MA, USA), HapAnalyzer version 1.0 (http://hap.ngri.go.kr/) and HelixTree (Golden Helix Inc., Bozeman, MT, USA). Lewontin's ID'l and $r^{2}$ were examined between all pairs of bi-allelic loci. The haplotypes and their frequencies were inferred using the expectationmaximization algorithm (17).

\section{Results}

In the analysis of demographics of IgAN patients, we found that pathological grade was significantly associated with proteinuria and podocyte foot process effacement $(\mathrm{P}=0.002$ and $<0.001$, respectively) (Table I).

The genotypic distributions of all SNPs in this study were consistent with HWE ( $>>0.05)$. The genotyping data of the 198 cases and 288 controls showed a significant association 
Table I. Demographics of the IgAN patients $(n=198)$.

\begin{tabular}{|c|c|c|c|c|c|c|c|c|c|}
\hline \multirow[t]{2}{*}{ Subgroups } & \multirow[t]{2}{*}{$\mathrm{n}(\%)$} & \multirow{2}{*}{$\begin{array}{l}\text { Male: } \\
\text { Female }\end{array}$} & \multirow{2}{*}{$\begin{array}{c}\text { Age }(\text { years }) \\
\text { mean } \pm \mathrm{SD}\end{array}$} & \multicolumn{6}{|c|}{ Pathological grade $(n)^{\mathrm{a}}$} \\
\hline & & & & I & II & III & IV & $\mathrm{V}$ & P-value \\
\hline \multicolumn{10}{|c|}{$\begin{array}{l}\text { Nephrotic range } \\
\text { proteinuria }^{b}\end{array}$} \\
\hline$(+)$ & $32(16.2)$ & $22: 10$ & $11.17 \pm 4.56$ & 14 & 10 & 7 & 1 & 0 & 0.002 \\
\hline$(-)$ & $166(83.8)$ & $95: 71$ & $12.93 \pm 5.25$ & 113 & 43 & 8 & 2 & 0 & \\
\hline \multicolumn{10}{|c|}{$\begin{array}{l}\text { Podocyte foot } \\
\text { process effacement }\end{array}$} \\
\hline$(+)$ & $82(41.4)$ & $52: 30$ & $13.45 \pm 5.66$ & 34 & 31 & 14 & 3 & 0 & $<0.001$ \\
\hline$(-)$ & $116(58.6)$ & $66: 50$ & $12.07 \pm 4.74$ & 93 & 22 & 1 & 0 & 0 & \\
\hline \multicolumn{10}{|c|}{$\begin{array}{l}\text { Pathological } \\
\text { progression }^{c}\end{array}$} \\
\hline$(+)$ & $18(9.1)$ & $15: 3$ & $16.17 \pm 7.78$ & 0 & 0 & 15 & 3 & 0 & $<0.001$ \\
\hline$(-)$ & $180(90.9)$ & 103:77 & $12.29 \pm 4.72$ & 127 & 53 & 0 & 0 & 0 & \\
\hline
\end{tabular}

${ }^{a}$ Modified H.S. Lee's glomerular grading system (15); the Mann-Whitney U test was performed comparing pathological grade between patient subgroups. ${ }^{b}$ Nephrotic range proteinuria indicates the largest level of proteinuria observed during the course of the disease. ${ }^{c}$ Patients were dichotomized according to pathological grade: pathologically mild (Grade I-II) and advanced (Grade III-IV) disease groups.

Table II. Logistic regression analysis of $I L 7 R$ polymorphisms in $\operatorname{IgAN}$ patients and healthy controls adjusted for gender and age.

\begin{tabular}{|c|c|c|c|c|c|}
\hline SNPs & $\operatorname{IgAN}, \mathrm{n}(\%)$ & Controls, n (\%) & Model & OR $(95 \% \mathrm{CI})$ & P-value \\
\hline \multicolumn{6}{|c|}{ rs1494558 Ile66Thr } \\
\hline \multicolumn{6}{|c|}{ Genotype } \\
\hline $\mathrm{A} / \mathrm{A}$ & $56(28.3)$ & $126(43.8)$ & Codominant & $1.63(1.24-2.14)$ & 0.0003 \\
\hline $\mathrm{A} / \mathrm{G}$ & $105(53.0)$ & $127(44.1)$ & Dominant & $2.01(1.36-2.97)$ & 0.0003 \\
\hline $\mathrm{G} / \mathrm{G}$ & 37 (18.7) & $35(12.1)$ & Recessive & $1.70(1.03-2.82)$ & 0.0390 \\
\hline \multicolumn{6}{|l|}{ Allele } \\
\hline A & $217(54.8)$ & $379(65.8)$ & & $1.59(1.22-2.06)$ & 0.0010 \\
\hline G & $179(45.2)$ & $197(34.2)$ & & & \\
\hline \multicolumn{6}{|c|}{ rs1494555 Val138Ile } \\
\hline \multicolumn{6}{|c|}{ Genotype } \\
\hline $\mathrm{C} / \mathrm{C}$ & $47(23.7)$ & $99(34.4)$ & Codominant & $1.48(1.13-1.94)$ & 0.0038 \\
\hline $\mathrm{T} / \mathrm{C}$ & $106(53.6)$ & $144(50.0)$ & Dominant & $1.70(1.13-2.56)$ & 0.0099 \\
\hline $\mathrm{T} / \mathrm{T}$ & 45 (22.7) & 45 (15.6) & Recessive & $1.63(1.03-2.60)$ & 0.0380 \\
\hline \multicolumn{6}{|l|}{ Allele } \\
\hline $\mathrm{C}$ & $200(50.5)$ & $342(59.4)$ & & $1.43(1.11-1.85)$ & 0.0060 \\
\hline $\mathrm{T}$ & $196(49.5)$ & $234(40.6)$ & & & \\
\hline
\end{tabular}

The statistically significant single nucleotide polymorphisms (SNPs) are shown. The two IL7R SNPs were genotyped in 198 IgAN patients and 288 healthy controls. Genotype distributions are shown as numbers (\%), odds ratios (OR) and 95\% confidence intervals (CI). P-values were obtained by logistic regression analysis using codominant, dominant and recessive models after controlling for gender and age.

between the presence of IgAN and both of the candidate missense SNPs by logistic regression analysis [rs1494558 (codominant model, OR=1.63, 95\% CI 1.24-2.14, $\mathrm{P}=0.0003$; dominant model, $\mathrm{OR}=2.01,95 \%$ CI 1.36-2.97, $\mathrm{P}=0.0003$; recessive model, $\mathrm{OR}=1.70,95 \%$ CI 1.03-2.82, $\mathrm{P}=0.0390$ ) and rs1494555 (codominant model, $\mathrm{OR}=1.48,95 \%$ CI 1.13-1.94, $\mathrm{P}=0.0038$; dominant model, $\mathrm{OR}=1.70,95 \%$ CI 1.13-2.56, $\mathrm{P}=0.0099$; recessive model, $\mathrm{OR}=1.63,95 \%$ CI 1.03-2.60, $\mathrm{P}=0.0380)$ ] (Table II). Upon comparison of the allelic frequencies, the $\mathrm{G}$ allele of rs1494558
$(\mathrm{OR}=1.59,95 \% \mathrm{CI} 1.22-2.06, \mathrm{P}=0.0010)$ and $\mathrm{T}$ allele of rs1494555 $(\mathrm{OR}=1.43,95 \%$ CI $1.11-1.85, \mathrm{P}=0.0060)$ were found to be risk alleles for $\operatorname{IgAN}$. In the measurement of pair-wise LD, one LD block was identified by the Gabriel method (18), and the block consisted of both rs1494558 and rs1494555 (data not shown). The haplotype analysis showed a statistical significance with the haplotype $\mathrm{AC}$ (codominant model, $\mathrm{OR}=0.69,95 \%$ CI 0.53 0.90, $\mathrm{P}=0.0066$; recessive model, $\mathrm{OR}=0.59,95 \%$ CI $0.40-0.89$, $\mathrm{P}=0.0124$ ) and the haplotype GT (codominant model, $\mathrm{OR}=1.62$, 
Table III. Haplotype analysis with polymorphisms of the IL7R gene.

\begin{tabular}{|c|c|c|c|c|c|c|c|}
\hline \multirow[t]{2}{*}{ Haplotype } & \multicolumn{2}{|c|}{$\mathrm{IgAN}$} & \multicolumn{2}{|c|}{ Controls } & \multirow[t]{2}{*}{ Model } & \multirow[t]{2}{*}{ OR $(95 \% \mathrm{CI})$} & \multirow[t]{2}{*}{ P-value } \\
\hline & $\mathrm{n}$ & Frequency & $\mathrm{n}$ & Frequency & & & \\
\hline \multicolumn{8}{|l|}{$\mathrm{AC}$} \\
\hline $\mathrm{H} / \mathrm{H}$ & 47 & & 99 & & Codominant & $0.69(0.53-0.90)$ & 0.0066 \\
\hline $\mathrm{H} /-$ & 106 & 0.51 & 143 & 0.59 & Dominant & $0.65(0.41-1.02)$ & 0.0618 \\
\hline$-/-$ & 45 & & 46 & & Recessive & $0.59(0.40-0.89)$ & 0.0124 \\
\hline \multicolumn{8}{|l|}{ GT } \\
\hline $\mathrm{H} / \mathrm{H}$ & 37 & & 34 & & Codominant & $1.62(1.24-2.12)$ & 0.0005 \\
\hline $\mathrm{H} /-$ & 105 & 0.45 & 128 & 0.34 & Dominant & $1.97(1.34-2.90)$ & 0.0006 \\
\hline$-1-$ & 56 & & 126 & & Recessive & $1.72(1.04-2.85)$ & 0.0362 \\
\hline \multicolumn{8}{|l|}{ AT } \\
\hline $\mathrm{H} / \mathrm{H}$ & 0 & & 2 & & Codominant & $0.64(0.36-1.15)$ & 0.1331 \\
\hline $\mathrm{H} /-$ & 17 & 0.04 & 34 & 0.07 & Dominant & $0.66(0.36-1.21)$ & 0.1761 \\
\hline$-/-$ & 181 & & 252 & & Recessive & $0.00(0.00-\mathrm{NA})$ & 0.9977 \\
\hline
\end{tabular}

OR, odds ratio; 95\% CI, 95\% confidence interval. Haplotype consists of rs1494558 and rs1494555 in IL7R.

Table IV. Logistic regression analysis of $I L 7 R$ polymorphisms in IgAN patients comparing groups with nephrotic and nonnephrotic range proteinuria ( $>40$ and $\leq 40 \mathrm{mg} / \mathrm{m}^{2} / \mathrm{h}$ ) adjusted for gender and age.

\begin{tabular}{|c|c|c|c|c|c|}
\hline SNPs & $\begin{array}{c}\text { Nephrotic proteinuria }^{a} \\
\mathrm{n}(\%)\end{array}$ & $\begin{array}{l}\text { Non-nephrotic proteinuria } \\
\mathrm{n}(\%)\end{array}$ & Model & OR $(95 \% \mathrm{CI})$ & P-value \\
\hline \multicolumn{6}{|c|}{ rs1494558 missense } \\
\hline \multicolumn{6}{|c|}{ Ile66Thr } \\
\hline \multicolumn{6}{|c|}{ Genotype } \\
\hline $\mathrm{A} / \mathrm{A}$ & $6(18.8)$ & $50(30.1)$ & Codominant & $1.92(1.06-3.46)$ & 0.0270 \\
\hline $\mathrm{A} / \mathrm{G}$ & $15(46.9)$ & $90(54.2)$ & Dominant & $1.81(0.69-4.74)$ & 0.2100 \\
\hline $\mathrm{G} / \mathrm{G}$ & $11(34.4)$ & $26(15.7)$ & Recessive & $2.81(1.18-6.67)$ & 0.0230 \\
\hline \multicolumn{6}{|l|}{ Allele } \\
\hline $\mathrm{A}$ & $27(42.2)$ & $190(57.2)$ & & $1.83(1.07-3.15)$ & 0.0270 \\
\hline G & $37(57.8)$ & $142(42.8)$ & & & \\
\hline \multicolumn{6}{|c|}{ rs1494555 missense } \\
\hline \multicolumn{6}{|c|}{ Val138Ile } \\
\hline \multicolumn{6}{|c|}{ Genotype } \\
\hline $\mathrm{C} / \mathrm{C}$ & $5(15.6)$ & $42(25.3)$ & Codominant & $1.81(1.00-3.28)$ & 0.0460 \\
\hline $\mathrm{T} / \mathrm{C}$ & $15(46.9)$ & $91(54.8)$ & Dominant & $1.73(0.61-4.88)$ & 0.0410 \\
\hline $\mathrm{T} / \mathrm{T}$ & $12(37.5)$ & $33(19.9)$ & Recessive & $0.70(0.32-1.51)$ & 0.3600 \\
\hline \multicolumn{6}{|l|}{ Allele } \\
\hline $\mathrm{C}$ & $25(39.1)$ & $175(52.7)$ & & $1.74(1.01-3.00)$ & 0.0460 \\
\hline $\mathrm{T}$ & $39(60.9)$ & $157(47.3)$ & & & \\
\hline
\end{tabular}

The statistically significant single nucleotide polymorphisms (SNPs) are shown, of a total of two IL7R SNPs genotyped in 198 IgAN patients. Genotype distributions are shown as numbers (\%), odds ratios (OR) and 95\% confidence intervals (CI). P-values were obtained by logistic regression analysis using codominant, dominant and recessive models after controlling for gender and age. Total numbers of SNPs differ as the genotypes of some SNPs were unreadable. ${ }^{\mathrm{a} N e p h r o t i c ~ r a n g e ~ p r o t e i n u r i a ~ g r o u p ~ w a s ~ d e f i n e d ~ a s ~ I g A N ~ p a t i e n t s ~ w i t h ~ p r o t e i n u r i a ~}>40 \mathrm{mg} / \mathrm{m}^{2} / \mathrm{h}$ during the course of the disease.

95\% CI 1.24-2.12, $\mathrm{P}=0.0005$; dominant model, $\mathrm{OR}=1.97,95 \%$ CI $1.34-2.90, \mathrm{P}=0.0006$; recessive model, $\mathrm{OR}=1.72,95 \% \mathrm{CI}$ 1.04-2.85, $\mathrm{P}=0.0362$ ) (Table III).

In order to verify our data, we calculated the sample power for each SNP using a genetic power calculator; the sample power was 0.9641 for rs1494558 (number of cases for $80 \%$ power $=109$ ) and 0.9662 for rs1494555 (number of cases for $80 \%$ power $=108$ ) with $\alpha=0.05$ and genotype relative risk $=2$-fold . Accordingly, our case-control study was sufficiently powered to detect a positive association. 
When the genotypic association between the SNPs and subgroups of $\operatorname{Ig} \mathrm{AN}$ patients was assessed, nephrotic range proteinuria ( $>40 \mathrm{mg} / \mathrm{m}^{2} / \mathrm{h}$ ) that developed during the course of the disease was found to be associated with rs1494558 (codominant model, $\mathrm{OR}=1.92,95 \% \mathrm{CI} 1.06-3.46, \mathrm{P}=0.0270$; recessive model, $\mathrm{OR}=2.81,95 \%$ CI $1.18-6.67, \mathrm{P}=0.0230$ ) (Table IV). The allelic frequency analysis showed that the $\mathrm{G}$ allele of rs1494558 $(\mathrm{OR}=1.83,95 \% \mathrm{CI} 1.07-3.15, \mathrm{P}=0.0270)$ and $\mathrm{T}$ allele of rs1494555 $(\mathrm{OR}=1.74,95 \%$ CI $1.01-3.00, \mathrm{P}=0.0460)$ were associated with the risk of developing nephrotic range proteinuria in IgAN patients. No significant difference was shown in clinical subgroup analysis in podocyte foot process effacement or pathological progression (data not shown).

\section{Discussion}

The relationship between the IL7/IL7R pathway and markers of inflammation has been observed in RA patients; influence on the clinical disease activity and the production of IL6, CRP, IL1b, IFN- $\gamma$ and TNF- $\alpha$ was noted $(7,11)$. In addition, IL7 may induce matrix metalloproteinase (MMP)-13 and matrix degradation $(12,19)$. A study of patients with SLE reported abnormal bone marrow-derived mesenchymal stem cells showing IL7 down-regulation (10). In addition, an inhibitory effect of IL7R has been reported in allergic inflammation processes (20).

Recently, an association of $I L 7 R$ polymorphisms with certain target diseases was reported in several studies. MS is the most studied disease, with well-replicated results (21-23). In these studies, the SNPs and their haplotypes of IL7R were suggested to be susceptibility and/or progression markers for MS, and the authors even speculated that overexpression of $I L 7 R$ possibly results in increased numbers of autoantigenspecific T cells $(21,22)$. Other studies have shown that SNPs of $I L 7$ and/or $I L 7 R$ are associated with susceptibility to RA, sarcoidosis and type 1 diabetes $(24,25)$. These reports suggest that the $I L 7 R$ locus may be involved in the pathogenesis of several diseases with an immunologic basis.

In the present study, we found a strong association between $I L 7 R$ SNPs and IgAN susceptibility. Haplotype (AC and TG) showed a strong association with IgAN susceptibility, as well. The calculated sample power was sufficient to detect this association. Furthermore, there was a weaker but significant association with the development of nephrotic range proteinuria in IgAN patients. When the allelic frequencies were compared to other populations, both SNPs had a similar distribution in the Japanese population from the HapMap database (http://www.hapmap.org). However, the A allele of rs1494558 and $\mathrm{C}$ allele of rs1494555 showed slightly higher frequencies than those of the other three populations used for comparison. Both alleles were investigated as protective alleles in the present analysis.

Two SNPs found to be significantly associated with IgAN pathogenesis, rs1494558 and rs1494555, are missense SNPs in the coding region that result in changes of amino acid sequences. Thus, there is a potential of affecting protein function or expression; consequently, the SNPs may be involved in the pathogenesis of $\operatorname{Ig} \mathrm{AN}$.

However, we could not demonstrate the association between pathological progression of IgAN and IL7R SNPs, despite their possible effects on the fibrotic process as reflected by a previously proposed function on MMP-13 and fibroblasts. In addition, even though an association with proteinuria was observed, no significant relationship with podocyte foot process effacement was found. These discrepancies could be a result of limitations of our study. Patients were enrolled by school screening urinalysis and, as reflected by the relatively mild pathological findings of our patients, they were in an early stage of disease. As the nephrotic proteinuria included late onset proteinuria that developed during the follow-up period, it may not correspond to the early stage biopsy findings.

In summary, there is evidence suggesting that $I L 7 R$ may be involved in the pathogenesis of $\operatorname{IgAN}$, but $I L 7 R$-related polymorphisms have not previously been studied in patients with IgAN. In the present study, two missense SNPs of $I L 7 R$, rs1494558 and rs1494555, were found to be significantly associated with both susceptibility to $\mathrm{IgAN}$ and nephrotic range proteinuria in $\operatorname{IgAN}$ patients.

\section{Acknowledgements}

The authors would like to gratefully acknowledge Dr Hyung-Jin Yoon for her advice.

\section{References}

1. Coppo R: Pediatric IgA nephropathy: clinical and therapeutic perspectives. Semin Nephrol 28: 18-26, 2008.

2. Alexopoulos E, Seron D, Hartley RB, Nolasco F and Cameron JS: The role of interstitial infiltrates in IgA nephropathy: a study with monoclonal antibodies. Nephrol Dial Transplant 4: 187-195, 1989.

3. Nikolic-Paterson DJ and Atkins RC: The role of macrophages in glomerulonephritis. Nephrol Dial Transplant 16 (Suppl 5): 3-7, 2001.

4. Fry TJ and Mackall CL: Interleukin-7: from bench to clinic. Blood 99: 3892-3904, 2002.

5. Ye SK, Maki K, Kitamura T, et al: Induction of germline transcription in the TCRgamma locus by Stat5: implications for accessibility control by the IL-7 receptor. Immunity 11: 213-223, 1999.

6. Gregory SG, Schmidt S, Seth P, et al: Interleukin 7 receptor alpha chain (IL7R) shows allelic and functional association with multiple sclerosis. Nat Genet 39: 1083-1091, 2007.

7. Van Roon JA, Glaudemans KA, Bijlsma JW and Lafeber FP: Interleukin 7 stimulates tumour necrosis factor alpha and Th1 cytokine production in joints of patients with rheumatoid arthritis. Ann Rheum Dis 62: 113-119, 2003.

8. Cox SN, Sallustio F, Serino G, et al: Altered modulation of WNT-beta-catenin and PI3K/Akt pathways in IgA nephropathy. Kidney Int 78: 396-407, 2010.

9. Goetz CA, Harmon IR, O'Neil JJ, Burchill MA and Farrar MA STAT5 activation underlies IL7 receptor-dependent B cell development. J Immunol 172: 4770-4778, 2004.

10. Sun LY, Zhang HY, Feng XB, Hou YY, Lu LW and Fan LM: Abnormality of bone marrow-derived mesenchymal stem cells in patients with systemic lupus erythematosus. Lupus 16: 121-128, 2007.

11. Van Roon JA, Hartgring SA, Wenting-van Wijk M, et al: Persistence of interleukin 7 activity and levels on tumour necrosis factor alpha blockade in patients with rheumatoid arthritis. Ann Rheum Dis 66: 664-669, 2007.

12. Van Roon JA and Lafeber FP: Role of interleukin-7 in degenerative and inflammatory joint diseases. Arthritis Res Ther 10: 107, 2008.

13. Maruyama K, Yoshida M, Nishio H, et al: Polymorphisms of renin-angiotensin system genes in childhood IgA nephropathy. Pediatr Nephrol 16: 350-355, 2001.

14. Nakanishi K, Sako M, Yata N, et al: A-20C angiotensinogen gene polymorphism and proteinuria in childhood IgA nephropathy. Pediatr Nephrol 19: 144-147, 2004 
15. Lee HS, Lee MS, Lee SM, et al: Histological grading of IgA nephropathy predicting renal outcome: revisiting H.S. Lee's glomerular grading system. Nephrol Dial Transplant 20: 342-348, 2005.

16. Sole X, Guino E, Valls J, Iniesta R and Moreno V: SNPStats: a web tool for the analysis of association studies. Bioinformatics 22: 1928-1929, 2006.

17. Stephens M, Smith NJ and Donnelly P: A new statistical method for haplotype reconstruction from population data. Am J Hum Genet 68: 978-989, 2001.

18. Gabriel SB, Schaffner SF, Nguyen H, et al: The structure of haplotype blocks in the human genome. Science 296: 2225-2229, 2002.

19. Long D, Blake S, Song XY, Lark M and Loeser RF: Human articular chondrocytes produce IL-7 and respond to IL-7 with increased production of matrix metalloproteinase-13. Arthritis Res Ther 10: R23, 2008.

20. Mobini R, Andersson BA, Erjefalt J, et al: A module-based analytical strategy to identify novel disease-associated genes shows an inhibitory role for interleukin 7 receptor in allergic inflammation. BMC Syst Biol 3: 19, 2009.
21. Lundmark F, Duvefelt K, Iacobaeus E, et al: Variation in interleukin 7 receptor alpha chain (IL7R) influences risk of multiple sclerosis. Nat Genet 39: 1108-1113, 2007.

22. Booth DR, Arthur AT, Teutsch SM, et al: Gene expression and genotyping studies implicate the interleukin 7 receptor in the pathogenesis of primary progressive multiple sclerosis. J Mol Med 83: 822-830, 2005.

23. Hoppenbrouwers IA, Aulchenko YS, Janssens AC, et al: Replication of CD58 and CLEC16A as genome-wide significant risk genes for multiple sclerosis. J Hum Genet 54: 676-680, 2009.

24. Heron M, Grutters JC, van Moorsel CH, et al: Variation in IL7R predisposes to sarcoid inflammation. Genes Immun 10: 647-653, 2009.

25. Santiago JL, Alizadeh BZ, Martinez A, et al: Study of the association between the CAPSL-IL7R locus and type 1 diabetes. Diabetologia 51: 1653-1658, 2008. 